\title{
Atividade residual de 2,4-D sobre a emergência de soja em solos com texturas distintas $^{1}$
}

\section{2,4-D residual activity over soybean emergence in soils with distinct textures}

\author{
Ferdinando Marcos Lima Silva ${ }^{2 *}$, Sidnei Douglas Cavalieri ${ }^{3}$, Alcebíades Rebouças São José ${ }^{4}$, \\ Santiago Miguel Ulloa ${ }^{5}$, Edivaldo Domingues Velini ${ }^{6}$
}

\begin{abstract}
Resumo - Objetivou-se com este trabalho avaliar a atividade residual do herbicida 2,4-D sobre a emergência de soja em solos de texturas distintas. Os experimentos, um com cada classe de solo (textura média e argilosa), foram conduzidos em casa de vegetação, em delineamento inteiramente casualizado, no esquema fatorial $6 \times 2+1$, sendo os tratamentos constituídos pela combinação de seis épocas de aplicação: $0,3,5,7,10$ e 14 dias antes da semeadura (DAS) da soja e duas dosagens de 2,4-D (502,5 e 1.005 g e.a. ha $\left.{ }^{-1}\right)$, mais uma testemunha absoluta sem aplicação do herbicida. A atividade residual do 2,4-D foi avaliada por meio do índice de velocidade de emergência (IVE), porcentagem de emergência (\%), fitointoxicação visual (\%), altura $(\mathrm{cm})$ e biomassa seca $(\mathrm{g})$ das plantas de soja aos 26 dias após a semeadura. Em ambos os solos, a atividade residual do 2,4-D foi observada, com variação em função da dosagem e do período de tempo entre a aplicação e a semeadura da soja. $\mathrm{O}$ efeito foi mais pronunciado nas plantas cultivadas em solo de textura média, onde houve maior fitointoxicação e redução da biomassa seca em relação à testemunha, principalmente, no tratamento onde o herbicida foi aplicado e a soja, cultivar V-Max, semeada em seguida.
\end{abstract}

Palavras-chave: Herbicida, persistência, fitointoxicação.

Abstract - This research aimed to evaluate the 2.4-D residual activity over soybean emergence in soils with distinct textures. The experiments, each one with a distinct soil type (clay sand and clay), were conducted in greenhouse conditions, in a randomized entirely design, in factorial scheme $6 \times 2+1$ with treatments constituted by the combination of six application period: $0,3,5,7$, 10 and 14 days before soybean sown (DBS) and two 2.4-D (502.5 e 1,005 g e.a. ha $\left.{ }^{-1}\right)$ doses,

\footnotetext{
* Autor para correspondência

${ }^{1}$ Recebido para publicação em 24/01/2011 e aceito em 14/03/2011.

${ }^{2}$ Eng. ${ }^{\circ}$ Agr. ${ }^{\circ}$, M.Sc., Doutorando em Agricultura. Depto. de Produção Vegetal, Faculdade de Ciências Agronômicas FCA/UNESP, 18603-970, Botucatu-SP, ferdinando.silva@yahoo.com.br

${ }^{3}$ Eng. ${ }^{\text {o Agr. }}$, D.Sc., Pesquisador da Embrapa Hortaliças. Rod. BR 060 km 9 Brasília/Anápolis, 70359-970, Brasília -DF, cavalieri@cnph.embrapa.br

${ }^{4}$ Eng. ${ }^{\circ}$ Agr. ${ }^{\circ}$, D.Sc., Professor da UESB. Departamento de Fitotecnia e Zootecnia, Estrada do Bem Querer KM 4, 45083-900, Vitória da Conquista - BA, alreboucas@ gmail.com

${ }^{5}$ Eng. ${ }^{\text {o }}$ Agr. ${ }^{\circ}$, Ph.D, Investigador ESPE/SENESCYT. Km 24 via Quevedo, Santo Domingo - Ecuador, santiago@huskers.unl.edu

${ }^{6}$ Professor Livre-Doente, FCA/UNESP, Depto. de Produção Vegetal, Faculdade de Ciências Agronômicas -

FCA/UNESP, 18603-970, Botucatu-SP, velini@ fca.unesp.br.
}

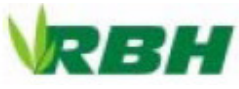


besides an absolute check without herbicide application. 2.4-D residual activity was evaluated through the emergence speed index (ESI), germination percentage (\%), visual phytointoxication $(\%)$, plant high $(\mathrm{cm})$ and soybean plants dry biomass (g) at 26 DBS. In both soil types, 2.4-D residual activity was observed, ranging in function of herbicide dose and time period between herbicide application and soybean sown. The effect was more pronounced in plants grown on cland soil where there was higher phytointoxication and reduction of dry biomass in relation to the check, mainly at the treatment where herbicide was sprayed and soybean genotype V-Max sowed in following.

Key words: Herbicide, persistence, phytointoxication.

\section{Introdução}

No manejo de plantas daninhas, seja após a cultura de entressafra, ou em áreas de pousio, é comum o uso de herbicidas de amplo espectro. Essa operação é a base do sucesso do sistema de semeadura direta que, se for bem realizada, irá proporcionar melhor controle, evitando que plantas daninhas importantes venham causar problemas futuros.

O herbicida 2,4-D (ácido 2,4diclorofenilacético) é um regulador de crescimento que possui efeito análogo ao hormônio auxina (Ashton \& Crafts, 1973). Pertence à família dos compostos fenóxicos, sendo sais ou ésteres de elevado peso molecular e baixa volatilidade, derivados do ácido fenoxiacético (Saad, 1978). Quando aplicado em dosagens relativamente baixas causa efeitos em pontos distantes daquele onde foi realizada a aplicação na planta devido à sua capacidade de translocação. É utilizado como herbicida por apresenta seletividade para plantas de folhas estreitas, tendo maior fitotoxicidade para espécies latiloliadas, sendo bastante utilizado em plantio direto, principalmente em mistura com outros herbicidas, como o glyphosate, na dessecação de plantas daninhas antes da semeadura da soja. A seletividade ocorre por mecanismos fisiológicos (Saad, 1978), possivelmente porque em dicotiledôneas essa auxina sintética não é metabolizada tão rapidamente quanto à auxina endógena, enquanto monocotiledôneas podem rapidamente inativar auxinas sintéticas por conjugação (Taiz \& Zeiger, 2004).
Sua toxidez se manifesta por meio de vários efeitos: epinastia das folhas, interrupção do crescimento e formação de necroses e raízes secundárias. Segundo Hanson \& Slife (1961), citados por Ashton \& Crafts (1973), quando plântulas de espécies susceptíveis são pulverizadas com 2,4-D o padrão de crescimento normal muda rapidamente: células meristemáticas param de se dividir, células em alongamento cessam o crescimento em comprimento, mas mantém a expansão radial.

Segundo Saad (1978), os principais efeitos do 2,4-D na planta são encarquilhamento das folhas, encurvamento da folha sobre a face inferior, as hastes se curvam para o solo e se tornam rígidas (às vezes trincadas) ou aumentam de volume em quase toda sua extensão, as cascas se fendem e dentro dessas fissuras aparecem galhos e raízes, os rebentos em desenvolvimento param de crescer, há o aparecimento de órgãos mal constituídos e as plantas perdem sua coloração verde, amarelecem e morrem.

Um fator importante a ser considerado no uso de 2,4-D é a sua persistência no solo, a qual apesar de ser considerada de curta a média e o período residual não exceder quatro semanas em solos argilosos e clima quente, quando aplicado em dosagens comerciais (Silva et al., 2007).

Objetivou-se com o trabalho avaliar o efeito fitotóxico do 2,4-D em plantas de soja (cultivar V-Max), após sua aplicação em solos 
de texturas distintas em diferentes períodos antes da semeadura.

\section{Material e Métodos}

O trabalho foi conduzido em maio de 2009, em casa de vegetação, no Núcleo de Pesquisas Avançadas em Matologia, pertencente à Faculdade de Ciência Agronômicas, UNESP, Botucatu-SP. Dois experimentos foram realizados, utilizando como unidades experimentais vasos de dois litros de capacidade, preenchidos com solos provenientes de duas diferentes classes, um de textura média com $20 \%$ de argila, $4 \%$ de silte e $76 \%$ de areia, apresentando na análise química $\mathrm{pH} \mathrm{CaCl} 2=4,3 ; \mathrm{H}^{+}+\mathrm{Al}^{3+}, \mathrm{Ca}^{2+}, \mathrm{Mg}^{2+}$ e $\mathrm{K}^{+}$ iguais a 58,$0 ; 10,0 ; 4,0$ e $0,6 \mathrm{mmol}_{\mathrm{c}} \mathrm{dm}^{-3}$, respectivamente, $\mathrm{P}=1,0 \mathrm{mg} \mathrm{dm}^{-3}$ e M.O. $=19$ $\mathrm{g} \mathrm{dm}^{-3} \mathrm{e}$; outro de textura argilosa com $54 \%$ de argila, $26 \%$ de silte e $11 \%$ de areia, apresentando na análise química $\mathrm{pH} \mathrm{CaCl}_{2}=$ 5,$9 ; \mathrm{H}^{+}+\mathrm{Al}^{3+}, \mathrm{Ca}^{2+}, \mathrm{Mg}^{2+}$ e $\mathrm{K}^{+}$iguais a 25,0 ; 53,$0 ; 28,0$ e $2,2 \mathrm{mmol}_{\mathrm{c}} \mathrm{dm}^{-3}$, respectivamente, $\mathrm{P}=17,0 \mathrm{mg} \mathrm{dm}{ }^{-3}$ e M.O. $=28 \mathrm{~g} \mathrm{dm}^{-3}$.

$\mathrm{O}$ delineamento experimental foi inteiramente casualizado, em esquema fatorial $6 \times 2+1$, em que tratamentos consistiram de seis diferentes períodos de aplicação do 2,4-D antes da semeadura da soja cultivar V-Max: 0 , $3,5,7,10$ e 14 dias antes da semeadura (DAS), duas doses do herbicida: 502,5 e 1.005 g e.a. ha ${ }^{-1}$, mais uma testemunha sem aplicação. Após a semeadura da soja (profundidade de $3-5 \mathrm{~cm}$ ) foi simulada uma chuva de $10 \mathrm{~mm}$.

A pulverização do herbicida 2,4-D e a simulação de chuva foram realizadas no NUPAM, através de um equipamento instalado em laboratório. A simulação da chuva foi realizada utilizando-se de uma bomba hidráulica de pressão constante com acionamento automático, a qual bombeia água armazenada de um reservatório até a barra e pontas de pulverização. A barra de pulverização foi constituída por quatro pontas XR 11002 VS, espaçadas de 0,5 m e posicionadas a $0,5 \mathrm{~m}$ de altura em relação à superfície dos alvos. Por ocasião da aplicação do 2,4-D, o sistema foi operado com pressão constante de 2 bar pressurizado por ar comprimido, velocidade de deslocamento de $3,6 \mathrm{~km} \mathrm{~h}^{-1}$ e consumo de calda correspondente a $200 \mathrm{~L} \mathrm{ha}^{-1}$.

A atividade residual do 2,4-D foi avaliada por meio do índice de velocidade de emergência (IVE); porcentagem de emergência (\%); fitointoxicação visual da soja (com notas variando de zero $0 \%-100 \%$, em que zero corresponde a nenhuma injúria e $100 \%$ a morte das plantas); altura e biomassa seca (BMS) das plantas de soja aos 26 dias após a semeadura, por ocasião do término do ensaio.

A análise estatística foi efetuada seguindo o modelo tradicional de fatorial com testemunha adicional (Gomes, 1990). Para verificar o efeito dos períodos de aplicação dentro de cada dosagem, empregou-se o teste $\mathrm{t}$, assim como para comparação desses em relação à testemunha absoluta, utilizou-se o teste de Dunnett, ambos a 5\% de probabilidade.

\section{Resultados e discussão}

No solo com textura média, as plantas de soja foram mais prejudicadas no período de aplicação de 0 DAS em todas as variáveis analisadas. Observou-se um menor percentual de emergência quando o 2,4-D foi aplicado na maior dosagem estudada (1.005 g e.a. ha $^{-1}$ ) aos 0 DAS (Tabela 1). Os tratamentos com a aplicação da maior dosagem aos 5, 7 e 10 DAS não diferiram da testemunha, mas apresentaram redução significativa na porcentagem de emergência em comparação aos demais tratamentos. Jaremtchuk et al. (2009) avaliando o efeito residual de 
flumioxazin sobre a emergência de plantas daninhas em solos de texturas distintas, observaram que a atividade residual do herbicida no controle do fluxo inicial de emergência variou em função da textura do solo, do período de tempo entre a aplicação e a semeadura das espécies e dosagem utilizada do herbicida.

Com relação ao IVE, esse foi menor no período de aplicação de 0 DAS para as duas dosagens avaliadas. Para 502,5 g e.a. ha ${ }^{-1}$, além do período de 0 DAS, o período de 7 DAS também apresentou redução significativa em relação à testemunha. Com 1.005 g e.a. ha $^{-1}$, todos os períodos de aplicação antes da semeadura apresentaram redução em relação à testemunha. Houve redução no IVE com o aumento da dosagem nos períodos de aplicação de 5 e 10 DAS, conforme Tabela 1.

Tabela 1. Índice de velocidade de emergência e porcentagem de emergência (\%) de plantas de soja, em solo com textura média, submetida a seis períodos entre a aplicação e semeadura.

\begin{tabular}{|c|c|c|c|c|}
\hline \multirow{3}{*}{ Período (DAS) } & \multicolumn{2}{|c|}{ IVE } & \multicolumn{2}{|c|}{ Porcentagem de emergência (\%) } \\
\hline & \multicolumn{4}{|c|}{ Dosagem (g e.a. ha $\left.{ }^{-1}\right)$} \\
\hline & 502,5 & 1.005 & 502,5 & 1.005 \\
\hline 0 & $1,05 \mathrm{Ba}^{*}$ & $0,33 \mathrm{Ba}^{*}$ & $20,00 \mathrm{Ba}$ & $7,50 \mathrm{Ca}^{*}$ \\
\hline 3 & $3,18 \mathrm{ABa}$ & $2,19 \mathrm{Aa}^{*}$ & $50,00 \mathrm{Aa}$ & $42,50 \mathrm{Aa}$ \\
\hline 5 & $3,78 \mathrm{ABa}$ & $0,71 \mathrm{ABb}^{*}$ & $62,50 \mathrm{Aa}$ & $15,00 \mathrm{BCb}$ \\
\hline 7 & $2,32 \mathrm{Ba}^{*}$ & $0,57 \mathrm{ABa}^{*}$ & $42,50 \mathrm{ABa}$ & $15,00 \mathrm{BCa}$ \\
\hline 10 & 4,22 Aa & $0,89 \mathrm{ABb}^{*}$ & $55,00 \mathrm{Aa}$ & $12,50 \mathrm{BCb}$ \\
\hline 14 & $3,41 \mathrm{ABa}$ & $2,22 \mathrm{Aa}^{*}$ & $47,50 \mathrm{Aa}$ & $37,50 \mathrm{ABa}$ \\
\hline Testemunha & \multicolumn{2}{|c|}{4,97} & \multicolumn{2}{|c|}{40,00} \\
\hline DMS (Dunnett - 5\%) & \multicolumn{2}{|c|}{2,24} & \multicolumn{2}{|c|}{30,26} \\
\hline DMS $(\mathrm{t}-5 \%)$ & \multicolumn{2}{|c|}{1,69} & \multicolumn{2}{|c|}{24,17} \\
\hline $\mathrm{CV}(\%)$ & \multicolumn{2}{|c|}{53,07} & \multicolumn{2}{|c|}{47,95} \\
\hline
\end{tabular}

Médias seguidas de mesma letra, maiúscula na coluna ou minúscula na linha, não diferem estatisticamente entre si pelo teste $\mathrm{t}$ a $5 \%$ de probabilidade. Médias seguidas por * foram diferentes da testemunha pelo teste de Dunnett a 5\% de probabilidade. DAS: dias antes da semeadura.

A fitointoxicação da soja (Tabela 2) foi observada em todos os períodos de aplicação em ambas as doses, apresentando diferença significativa em relação à testemunha. Os sintomas visuais de fitointoxicação observados foram encarquilhamento das folhas e epinastia dos pecíolos. Tais sintomas também foram observados por Constantin et al. (2007) em trabalho simulando deriva de 2,4-D na cultura do algodoeiro. Novamente, aos 5 e 10 DAS,
1005 g e.a. ha $^{-1}$ de 2,4-D promoveu aumento significativo de injurias às plantas. De acordo com Guevara (1998), o 2,4-D aplicado em pósemergência causa drástico estrangulamento do câmbio, e isso se deve principalmente à inibição da elongação do ramo principal, a qual resulta na diminuição da formação e elongação de nós. 
Todos os períodos de aplicação apresentaram redução de altura para $1.005 \mathrm{~g}$ e.a. ha $^{-1}$ de 2,4-D em comparação à testemunha (Tabela 2). Para 502,5 g e.a. ha ${ }^{-1}$ houve diferença significativa em comparação à testemunha aos 0 e 7 DAS. O aumento da dose promoveu a redução da altura das plantas de soja em todos os períodos de aplicação, mas essa redução foi significativa apenas no período de 7 DAS.

Comparando-se à testemunha, a BMS foi menor em todos os tratamentos, como pode ser observado na Tabela 2, sendo os menores valores observados no período de aplicação de 0 DAS. Houve efeito significativo do aumento da dosagem na redução da BMS nos períodos de aplicação 5 e 10 DAS. Os valores de biomassa apresentaram relação positiva com a porcentagem de fitointoxicação, demonstrando que a avaliação visual foi um método rápido e confiável para a avaliação de fitointoxicação.

Tabela 2. Fitointoxicação (\%), altura $(\mathrm{cm})$ e biomassa seca de plantas de soja, em solo com textura média, submetida a seis períodos entre a aplicação e semeadura.

\begin{tabular}{|c|c|c|c|c|c|c|}
\hline \multirow{3}{*}{ Período (DAS) } & \multicolumn{2}{|c|}{ Fitointoxicação (\%) } & \multicolumn{2}{|c|}{ Altura $(\mathrm{cm})$} & \multicolumn{2}{|c|}{ Biomassa seca (g) } \\
\hline & \multicolumn{6}{|c|}{ Dosagem (g e.a. ha $^{-1}$ ) } \\
\hline & 502,5 & 1.005 & 502,5 & 1.005 & 502,5 & 1.005 \\
\hline 0 & $83,75 \mathrm{Aa}^{*}$ & $94,25 \mathrm{Aa}^{*}$ & $5,65 \mathrm{Ba}^{*}$ & $4,25 \mathrm{Ba}^{*}$ & $0,21 \mathrm{Ca}^{*}$ & $0,06 \mathrm{Ba}^{*}$ \\
\hline 3 & $45,00 \mathrm{Ba}^{*}$ & $63,00 \mathrm{Ba}^{*}$ & $12,18 \mathrm{Aa}$ & $9,48 \mathrm{Aa}^{*}$ & $0,66 \mathrm{ABa}^{*}$ & $0,49 \mathrm{Aa}^{*}$ \\
\hline 5 & $46,75 \mathrm{Bb}^{*}$ & $88,50 \mathrm{ABa}^{*}$ & $11,80 \mathrm{Aa}$ & $7,42 \mathrm{ABa}^{*}$ & $0,84 \mathrm{ABa}^{*}$ & $0,18 \mathrm{ABb}^{*}$ \\
\hline 7 & $75,75 \mathrm{Aa}^{*}$ & $89,50 \mathrm{ABa}^{*}$ & 9,93 $\mathrm{ABa}^{*}$ & $4,18 \mathrm{Bb}^{*}$ & $0,49 \mathrm{BCa}^{*}$ & $0,14 \mathrm{ABa}^{*}$ \\
\hline 10 & $43,50 \mathrm{Bb}^{*}$ & $84,75 \mathrm{ABa}^{*}$ & $12,68 \mathrm{Aa}$ & $9,25 \mathrm{Aa}^{*}$ & 0,89 $\mathrm{Aa}^{*}$ & $0,16 \mathrm{ABb}^{*}$ \\
\hline 14 & $50,00 \mathrm{Ba}^{*}$ & $67,50 \mathrm{Ba}^{*}$ & $11,50 \mathrm{Aa}$ & 9,98 $\mathrm{Aa}^{*}$ & $0,70 \mathrm{ABa}^{*}$ & $0,45 \mathrm{Aa}^{*}$ \\
\hline Testemunha & \multicolumn{2}{|c|}{0,00} & \multicolumn{2}{|c|}{15,93} & \multicolumn{2}{|c|}{1,70} \\
\hline DMS (Dunnett - 5\%) & \multicolumn{2}{|c|}{27,27} & \multicolumn{2}{|c|}{5,76} & \multicolumn{2}{|c|}{0,51} \\
\hline DMS $(\mathrm{t}-5 \%)$ & \multicolumn{2}{|c|}{22,14} & \multicolumn{2}{|c|}{4,59} & \multicolumn{2}{|c|}{0,36} \\
\hline $\mathrm{CV}(\%)$ & \multicolumn{2}{|c|}{23,17} & \multicolumn{2}{|c|}{32,80} & \multicolumn{2}{|c|}{52,09} \\
\hline
\end{tabular}

Médias seguidas de mesma letra, maiúscula na coluna ou minúscula na linha, não diferem estatisticamente entre si pelo teste t a $5 \%$ de probabilidade. Médias seguidas por * foram diferentes da testemunha pelo teste de Dunnett a 5\% de probabilidade. DAS: dias antes da semeadura.

No solo de textura argilosa, alguns tratamentos promoveram aumento na porcentagem de emergência (Tabela 3), havendo, porém, diferença significativa em relação à testemunha apenas na aplicação de 502,5 g e.a. ha ${ }^{-1}$ aos 0 DAS, em que houve menor percentual de emergência. Com relação ao índice de velocidade de emergência, houve redução significativa dessa variável em relação à testemunha apenas aos 0 DAS para ambas dosagens de 2,4-D. Aos 3 DAS, a maior dosagem do herbicida ainda apresentou redução do IVE em comparação aos demais períodos e à menor dose do 2,4-D.

Os maiores valores de fitointoxicação (Tabela 4) foram observados no período de 0 DAS em ambas as dosagens em solo de textura argilosa. A fitointoxicação foi significativamente maior com 1005 g e.a. ha ${ }^{-1}$ em relação a 502,5 g e.a. ha ${ }^{-1}$ no período de 
aplicação de 3 DAS. Também observou-se que para 502,5 g e.a. ha $^{-1}$ houve redução significativa da altura apenas no período de 0 DAS, assim como para $1.005 \mathrm{~g}$ e.a. $\mathrm{ha}^{-1}$. O menor valor de altura também foi observado no período de 0 DAS. O aumento da dose do herbicida promoveu redução significativa na altura da soja no período de 3 DAS. D'Antonino et al. (2009) utilizando pepino como planta indicadora encontrou resíduo de
2,4-D em solo tratado com esse herbicida um dia após sua aplicação.

Com 502,5 g e.a. ha $^{-1}$ de 2,4-D, houve redução significativa da BMS apenas no período de 0 DAS. O aumento da dosagem reduziu significativamente a BMS nos períodos de aplicação 3 e 14 DAS. Para 1.005 g e.a. ha ${ }^{-1}$, houve redução da BMS no período de 0 e 3 DAS (Tabela 4).

Tabela 3. Índice de velocidade de emergência e porcentagem de emergência (\%) de plantas de soja, em solo com textura argilosa, submetida a seis períodos entre a aplicação e semeadura.

\begin{tabular}{|c|c|c|c|c|}
\hline \multirow{3}{*}{ Período (DAS) } & \multicolumn{2}{|c|}{ IVE } & \multicolumn{2}{|c|}{ Porcentagem de emergência $(\%)$} \\
\hline & \multicolumn{4}{|c|}{ Dosagem (g e.a. ha $\left.{ }^{-1}\right)$} \\
\hline & 502,5 & 1.005 & 502,5 & 1.005 \\
\hline 0 & $2,80 \mathrm{Ba}^{*}$ & $3,23 \mathrm{Ba}^{*}$ & $26,00 \mathrm{Ba}^{*}$ & $62,50 \mathrm{Ba}$ \\
\hline 3 & $10,79 \mathrm{Aa}$ & $6,21 \mathrm{Bb}$ & $77,50 \mathrm{Aa}$ & $62,50 \mathrm{Ba}$ \\
\hline 5 & $11,50 \mathrm{Aa}$ & $10,66 \mathrm{Aa}$ & $80,00 \mathrm{Aa}$ & $92,50 \mathrm{Aa}$ \\
\hline 7 & $8,82 \mathrm{Aa}$ & 9,19 ABa & $72,50 \mathrm{Aa}$ & $80,00 \mathrm{ABa}$ \\
\hline 10 & 9,94 Aa & $9,15 \mathrm{ABa}$ & $77,50 \mathrm{Aa}$ & $72,50 \mathrm{ABa}$ \\
\hline 14 & $11,25 \mathrm{Aa}$ & $9,01 \mathrm{ABa}$ & $90,00 \mathrm{Aa}$ & $87,50 \mathrm{Aa}$ \\
\hline Testemunha & \multicolumn{2}{|c|}{$7, \overline{67}$} & \multicolumn{2}{|c|}{67,50} \\
\hline DMS (Dunnett - 5\%) & \multicolumn{2}{|c|}{4,17} & \multicolumn{2}{|c|}{30,28} \\
\hline DMS $(\mathrm{t}-5 \%)$ & \multicolumn{2}{|c|}{3,20} & \multicolumn{2}{|c|}{23,54} \\
\hline $\mathrm{CV}(\%)$ & \multicolumn{2}{|c|}{26,76} & \multicolumn{2}{|c|}{22,36} \\
\hline
\end{tabular}

Médias seguidas de mesma letra, maiúscula na coluna ou minúscula na linha, não diferem estatisticamente entre si pelo teste $\mathrm{t}$ a $5 \%$ de probabilidade. Médias seguidas por * foram diferentes da testemunha pelo teste de Dunnett a 5\% de probabilidade. DAS: dias antes da semeadura. 
Tabela 4. Fitointoxicação (\%), altura $(\mathrm{cm})$ e biomassa seca de plantas de soja, em solo com textura argilosa, submetida a seis períodos entre a aplicação e semeadura.

\begin{tabular}{|c|c|c|c|c|c|c|}
\hline \multirow{3}{*}{ Período (DAS) } & \multicolumn{2}{|c|}{ Fitointoxicação (\%) } & \multicolumn{2}{|c|}{ Altura $(\mathrm{cm})$} & \multicolumn{2}{|c|}{ Biomassa seca (g) } \\
\hline & \multicolumn{6}{|c|}{ Dosagem (g e.a. ha $\left.{ }^{-1}\right)$} \\
\hline & 502,5 & 1.005 & 502,5 & 1.005 & 502,5 & 1.005 \\
\hline 0 & $59,50 \mathrm{Aa}^{*}$ & $62,00 \mathrm{Aa}^{*}$ & $8,60 \mathrm{Ba}^{*}$ & $9,95 \mathrm{Ba}^{*}$ & $0,44 \mathrm{Ba}^{*}$ & $0,43 \mathrm{Ba}^{*}$ \\
\hline 3 & $9,50 \mathrm{Bb}$ & $32,50 \mathrm{Ba}^{*}$ & $17,23 \mathrm{Aa}$ & $12,48 \mathrm{ABb}^{*}$ & $1,48 \mathrm{Aa}$ & $0,78 \mathrm{Bb}^{*}$ \\
\hline 5 & $10,75 \mathrm{Ba}$ & $13,00 \mathrm{Ca}$ & $15,26 \mathrm{Aa}$ & $13,25 \mathrm{ABa}$ & $1,81 \mathrm{Aa}$ & $1,42 \mathrm{Aa}$ \\
\hline 7 & 7,75 Ba & $18,25 \mathrm{BCa}$ & $15,23 \mathrm{Aa}$ & $12,55 \mathrm{ABa}^{*}$ & $1,38 \mathrm{Aa}$ & $1,23 \mathrm{ABa}$ \\
\hline 10 & $13,75 \mathrm{Ba}$ & $18,75 \mathrm{BCa}$ & $13,95 \mathrm{Aa}$ & $14,55 \mathrm{Aa}$ & $1,52 \mathrm{Aa}$ & $1,41 \mathrm{Aa}$ \\
\hline 14 & $11,25 \mathrm{Ba}$ & $24,75 \mathrm{BCa}^{*}$ & $14,20 \mathrm{Aa}$ & $13,00 \mathrm{Aba}$ & $1,66 \mathrm{Aa}$ & $1,19 \mathrm{ABb}$ \\
\hline Testemunha & \multicolumn{2}{|r|}{0,00} & \multicolumn{2}{|c|}{17,20} & \multicolumn{2}{|c|}{1,56} \\
\hline DMS (Dunnett - 5\%) & \multicolumn{2}{|c|}{21,67} & \multicolumn{2}{|c|}{4,30} & \multicolumn{2}{|c|}{0,62} \\
\hline DMS $(\mathrm{t}-5 \%)$ & \multicolumn{2}{|c|}{17,59} & \multicolumn{2}{|c|}{3,49} & \multicolumn{2}{|c|}{0,46} \\
\hline $\mathrm{CV}(\%)$ & \multicolumn{2}{|c|}{54,38} & \multicolumn{2}{|c|}{17,14} & \multicolumn{2}{|c|}{27,08} \\
\hline
\end{tabular}

Médias seguidas de mesma letra, maiúscula na coluna ou minúscula na linha, não diferem estatisticamente entre si pelo teste $\mathrm{t}$ a $5 \%$ de probabilidade. Médias seguidas por * foram diferentes da testemunha pelo teste de Dunnett a $5 \%$ de probabilidade. DAS: dias antes da semeadura.

Além da textura do solo, Vieira et al. (1999) salientaram a importância da presença da matéria orgânica na adsorção do 2,4-D já que esse herbicida é adsorvido preferencialmente pela mesma. Isso ajuda a explicar o menor efeito do herbicida sobre as plantas de soja no solo com textura argilosa, uma vez que apresentavam maior teor de MO.

$\mathrm{O}$ efeito residual do 2,4-D sobre o desenvolvimento inicial da soja pode ser observado em todos os tratamentos com variação em função do tipo de solo e período de tempo entre a aplicação e semeadura da soja. Os resultados confirmaram as recomendações de Rodrigues \& Almeida (2005) para a utilização de 2,4-D no manejo de semeadura direta, em que deve-se esperar, no mínimo, 10 dias entre a aplicação e a semeadura da soja. Assim como também, quanto à possibilidade de ocorrência de danos à cultura em condições de baixa umidade no solo. Resultados similares foram encontrados por Silva et al. (2007) que encontraram atividade residual do 2,4-D nas primeiras semanas após sua aplicação.

\section{Conclusões}

Nas condições em que o estudo foi realizado, verificou-se que o efeito residual de 2,4-D ficou mais evidente nas plantas de soja, cultivar V-Max, em solo de textura média, apresentando alta fitointoxicação e redução da biomassa seca, principalmente no tratamento onde o herbicida foi aplicado e a soja semeada logo em seguida. A dessecação com 2,4-D muito próxima da semeadura da soja, pode acarretar efeitos fitotóxicos à cultura em decorrência do residual desse herbicida. 


\section{Referências}

ASHTON, F.M.; CRAFTS, A.S. Mode of action of herbicides. New York: John Wiley, 1973. 504p.

CONSTANTIN, J. et al. Efeito de subdoses de 2,4-D na produtividade do algodão e suscetibilidade da cultura em função de seu estádio de desenvolvimento. Engenharia Agrícola, v.27, n.esp., p.24-29, 2007.

D'ANTONINO et al. Efeitos de culturas na persistência de herbicidas auxínicos no solo. Planta Daninha, v. 27, n.2, p.371-378, 2009.

GOMES, F.P. Curso de estatística experimental. 13.ed. Piracicaba: Nobel, 1990. $468 \mathrm{p}$.

GUEVARA, G. Efecto del 2,4-D sobre el algodón. Saenz Peña: Instituto Nacional de Tecnologia Agropecuária. 1998. 12 p. (Boletim Técnico, 12).

HANSON, J.B.; SLIFE, F.W. How does 2,4-D kill a plant? Illinois Research v.3, n.3, p.3-4, 1961.

JAREMTCHUK, C.C. et al. Efeito residual de flumioxazin sobre a emergência de plantas daninhas em solos de texturas distintas. Planta Daninha, v.27, n.1, p.191-196, 2009.

RODRIGUES, B.N.; ALMEIDA, F.S. Guia de herbicidas. 5a edição. Londrina: Grarfmake, 2005. 592p.

SAAD, O. A vez dos herbicidas. 2.ed. São Paulo: Nobel, 1978. 267p.

SILVA, A.A. et al. Herbicidas: classificação e mecanismo de ação. In: SILVA, A. A.; SILVA, J. F. (Eds.) Tópicos em manejo de plantas daninhas. Viçosa, MG: Universidade Federal de Viçosa, 2007. p. 83-148.

TAIZ, L.; ZEIGER, E. Fisiologia vegetal. 3. ed. Porto Alegre: Artmed, 2004. 719p.

VIEIRA, E.M. et al. Estudo da adsorção/dessorção do ácido 2,4 diclorofenoxiacético (2,4D) em solo na ausência e presença de matéria orgânica. Química Nova, v.22, n.3, p.305-308, 1999. 